Case Report

\title{
Pleomorphic Adenoma of Breast: A Radiological and Pathological Study of a Common Tumor in an Uncommon Location
}

\author{
Paula S. Ginter, ${ }^{1}$ Theresa Scognamiglio, ${ }^{1}$ Pamela Tauchi-Nishi, ${ }^{2}$ \\ Lilian B. Antonio, ${ }^{1}$ and Syed A. Hoda ${ }^{1}$ \\ ${ }^{1}$ Department of Pathology and Laboratory Medicine, Weill Cornell Medical College, New York, NY 10065, USA \\ ${ }^{2}$ Department of Pathology, The Queen's Medical Center, Honolulu, HI 96813, USA
}

Correspondence should be addressed to Paula S. Ginter; psg9003@nyp.org

Received 29 December 2014; Accepted 7 February 2015

Academic Editor: Sami Shousha

Copyright (C) 2015 Paula S. Ginter et al. This is an open access article distributed under the Creative Commons Attribution License, which permits unrestricted use, distribution, and reproduction in any medium, provided the original work is properly cited.

\begin{abstract}
Pleomorphic adenoma occurs commonly in the major salivary glands but is uncommonly encountered in the breast. In both of these locations, the tumor is typically grossly circumscribed and has a "mixed" histological appearance, being composed of myoepithelial and epithelial components amid a myxochondroid matrix. Herein, we report a case of pleomorphic adenoma of the breast which was preoperatively thought to represent a fibroadenoma on clinical and radiological grounds. It is the rarity of the tumor in the breast, rather than its histological appearance, that causes diagnostic difficulty.
\end{abstract}

\section{Introduction}

Pleomorphic adenoma (PA) is a benign neoplasm which most commonly occurs in the parotid gland but has only rarely been described in the breast. PA is composed of two components, that is, myoepithelial and epithelial (hence, the synonym: mixed tumor). Both components are embedded in chondroid stroma [1]. The rarity of PA in the breast, as well as its unusual appearance, has contributed to misdiagnosis in this location $[2,3]$. PAs are considered to be a variant of intraductal papilloma or adenomyoepithelioma [4] and are typically found in the subareolar region $[5,6]$. PAs are generally indolent. Rare examples of malignant PA (i.e., carcinoma ex PA) in the breast have been reported [7].

\section{Case Report}

A 42-year-old woman presented with a slowly growing palpable mass in the left breast. An ultrasound showed a wellcircumscribed, hypoechoic mass that spanned $1.4 \mathrm{~cm}$ and was located at 1:00, $2 \mathrm{~cm}$ from the nipple (Figure 1(a)). The preoperative clinical and radiological impression was that of a fibroadenoma. A firm, well-circumscribed, $1.2 \mathrm{~cm}$, mass was excised. Serial sectioning revealed whitish, homogeneous, cut surfaces (Figure 1(b), bar: $1.0 \mathrm{~cm}$ ). Microscopically, the tumor was comprised of an admixture of stromal and epithelial elements. The dominant stromal component was characterized by bland spindled myoepithelial cells embedded in a largely myxoid, focally chondroid, matrix (Figures 1 (c) and $1(\mathrm{~d})$ ). The epithelial component, represented by scattered compressed glands interspersed in the stroma, was cytologically insipid and mitotically quiescent (Figure 1(e)). The native breast glandular parenchyma, minimally represented in the specimen at the perimeter of the tumor, was inactive. There was no evidence of associated papilloma or adenomyoepithelioma. The lesional stromal myoepithelial cells and the periglandular myoepithelial cells were immunoreactive for calponin (Figure 1(f)), high molecular weight cytokeratin (CK-K903), and $\mathrm{p} 63$. The gross, histological and immunohistochemical findings in this tumor were characteristic of mammary PA. The most recent follow-up ultrasound examination of the ipsilateral breast, performed 5 months following the excisional biopsy, showed no evidence of residual or recurrent disease. 


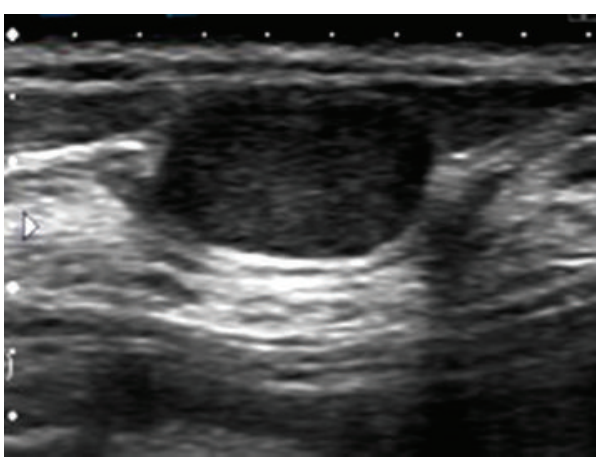

(a)

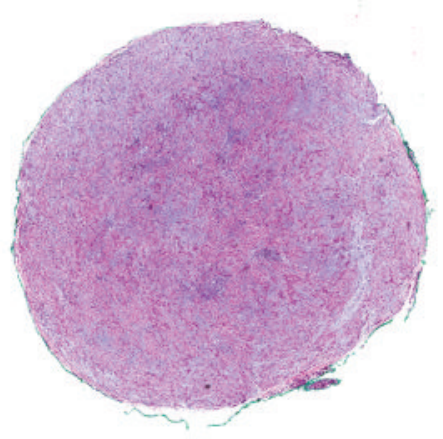

(c)

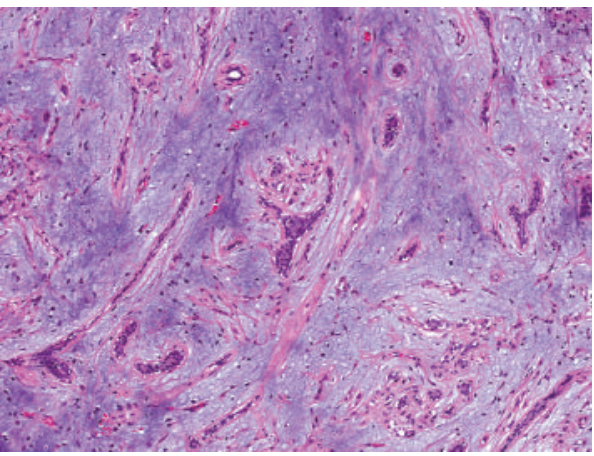

(e)

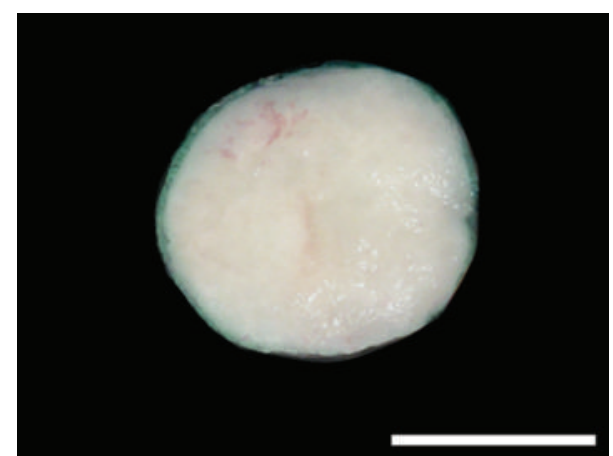

(b)

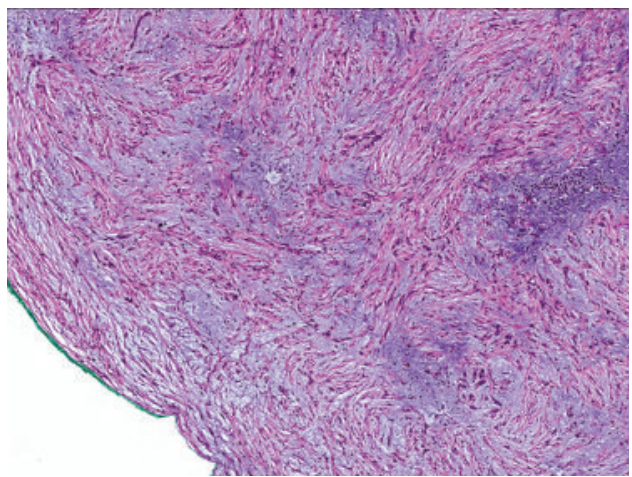

(d)

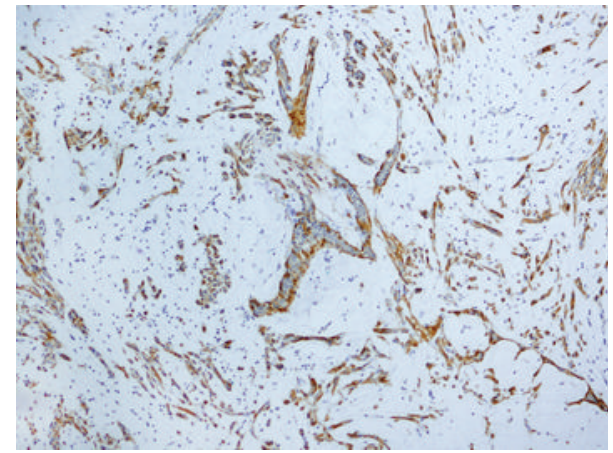

(f)

Figure 1: Pleomorphic adenoma of the breast. (a) Ultrasound showing a well-circumscribed, hypoechoic mass. (b) Cut sectioning showed a firm, well-circumscribed mass with whitish, homogeneous surface (bar: $1.0 \mathrm{~cm})$. ((c) and (d)) Histological section shows the tumor to be composed of stromal and epithelial elements. The stromal component is comprised of bland spindle cells embedded in a myxochondroid matrix. (e) The epithelial component shows scattered compressed glands interspersed in the stroma. (f) Calponin immunostain highlights stromal and periglandular myoepithelial cells. The epithelial cells are negative for calponin.

\section{Discussion}

PA is the most common benign tumor of the parotid gland; however, it is among the least common neoplasms of the mammary gland. In the latter location, it afflicts primarily adult females and typically presents as a solitary palpable central mass $[3,8,9]$. Published cases of mammary PAs have ranged in size from $0.6 \mathrm{~cm}$ to $17 \mathrm{~cm}$, with most spanning $\sim 2 \mathrm{~cm}$ [10-12]. PA can also occur, albeit most uncommonly, in the skin, vulva, and upper respiratory tract [13]. In all its primary locations, PA generally behaves in an indolent manner and neither recurs nor metastasizes following complete resection; nevertheless, at least 3 cases of malignant PA (i.e., carcinoma ex PA) in the breast have been reported [7]. In these cases of carcinoma ex PA, areas diagnostic of PA were present in addition to areas with histological features of malignancy as defined in the salivary gland counterpart [14]. The latter include infiltrative growth pattern, necrosis, marked cytological atypia, high mitotic rate, and presence of atypical mitoses [7]. It is notable that benign PAs of the breast have been mistaken for mucinous carcinoma [3] and metaplastic carcinoma [2], on limited samples of fine 
needle aspirates (FNA) and needle core biopsies (NCB), respectively-the perfidious myxoid matrix proving to be the diagnostic pitfall in these instances.

Although several sporadic clonal changes have been reported in PAs of the salivary gland, the most common chromosomal rearrangements therein involve 8q12, containing the target gene PLAG1, or 12q13-15 with the target gene HMGA2 [15]. The detection of PLAG1 and HMGAs translocations by either reverse transcriptase-polymerase chain reaction or fluorescent in situ hybridization can be useful in confirming the diagnosis in the rare diagnostically challenging PA in the salivary glands; however, the diagnostic utility of this technique at other sites remains uncertain.

In summary, we report a case of mammary PA-which was clinically and radiologically suspected to be a fibroadenoma. Histologically, the tumor demonstrated the characteristic histopathological features of a PA. Pathologists should keep this tumor in mind whenever a tumor with prominent myxochondroid appearance is encountered-particularly in aspiration cytology or needle core biopsy material.

\section{Conflict of Interests}

The authors declare that there is no conflict of interests regarding the publication of this paper.

\section{Acknowledgment}

Dr. Jeffrey K. Yeoh kindly provided the ultrasound image and clinical follow-up information.

\section{References}

[1] M. Reid-Nicholson, I. Bleiweiss, B. Pace, V. Azueta, and S. Jaffer, "Pleomorphic adenoma of the breast: a case report and distinction from mucinous carcinoma," Archives of Pathology and Laboratory Medicine, vol. 127, no. 4, pp. 474-477, 2003.

[2] A. Djakovic, J. B. Engel, E. Geisinger, A. Honig, A. Tschammler, and J. Dietl, "Pleomorphic adenoma of the breast initially misdiagnosed as metaplastic carcinoma in preoperative stereotactic biopsy: a case report and review of the literature," European Journal of Gynaecological Oncology, vol. 32, no. 4, pp. 427-430, 2011.

[3] P. Iyengar, H. S. Cody III, and E. Brogi, "Pleomorphic adenoma of the breast: case report and review of the literature," Diagnostic Cytopathology, vol. 33, no. 6, pp. 416-420, 2005.

[4] P. P. Rosen, S. A. Hoda, E. Brogi, and F. C. Koerner, Rosen'S Breast Pathology, Lippincott Williams \& Wilkins, Philadelphia, $\mathrm{Pa}$, USA, 4th edition, 2014.

[5] T. Narita and K. Matsuda, "Pleomorphic adenoma of the breast: case report and review of the literature," Pathology International, vol. 45, no. 6, pp. 441-447, 1995.

[6] M. Nevado, J. I. Lopez, M. P. Dominguez, C. Ballestin, and H. Garcia, "Pleomorphic adenoma of the breast. Case report," APMIS: Acta Pathologica, Microbiologica, et Immunologica Scandinavica, vol. 99, no. 9, pp. 866-868, 1991.

[7] M. M. Hayes, D. Lesack, C. Girardet, M. del Vecchio, and V. Eusebi, "Carcinoma ex-pleomorphic adenoma of the breast. Report of three cases suggesting a relationship to metaplastic carcinoma of matrix-producing type," Virchows Archiv, vol. 446, no. 2, pp. 142-149, 2005.

[8] M. P. Foschini and T. Krausz, "Salivary gland-type tumors of the breast: a spectrum of benign and malignant tumors including 'triple negative carcinomas' of low malignant potential,' Seminars in Diagnostic Pathology, vol. 27, no. 1, pp. 77-90, 2010.

[9] K. Sato, Y. Ueda, M. Shimasaki et al., "Pleomorphic adenoma (benign mixed tumor) of the breast: a case report and review of the literature," Pathology-Research and Practice, vol. 201, no. 4, pp. 333-339, 2005.

[10] K. T. K. Chen, "Pleomorphic adenoma of the breast," The American Journal of Clinical Pathology, vol. 93, no. 6, pp. 792-794, 1990.

[11] N. M. Diaz, R. W. McDivitt, and M. R. Wick, "Pleomorphic adenoma of the breast: a clinicopathologic and immunohistochemical study of 10 cases," Human Pathology, vol. 22, no. 12, pp. 1206-1214, 1991.

[12] T. Khamechian, J. Alizargar, and T. Mazoochi, "Reporting a rare case of pleomorphic adenoma of the breast," Case Reports in Medicine, vol. 2014, Article ID 387183, 4 pages, 2014.

[13] A. Su, S. K. Apple, and N. A. Moatamed, "Pleomorphic adenoma of the vulva, clinical reminder of a rare occurrence," Rare Tumors, vol. 4, no. 1, article e16, 2012.

[14] L. Barnes, World Health Organization, and International Agency for Research on Cancer, Pathology and Genetics of Head and Neck Tumours, IARC Press, Lyon, France, 2005.

[15] F. Persson, Y. Andrén, M. Winnes et al., "High-resolution genomic profiling of adenomas and carcinomas of the salivary glands reveals amplification, rearrangement, and fusion of HMGA2," Genes Chromosomes \& Cancer, vol. 48, no. 1, pp. 6982, 2009. 


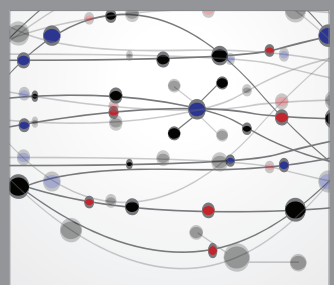

The Scientific World Journal
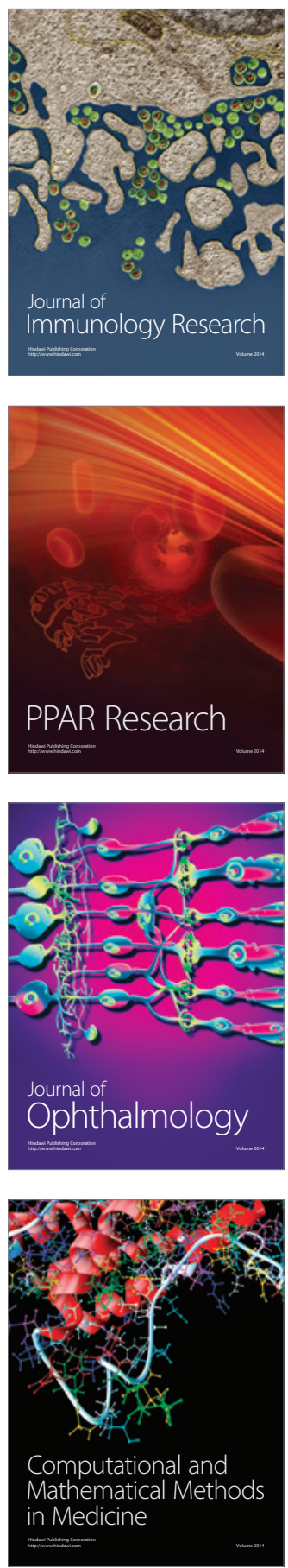

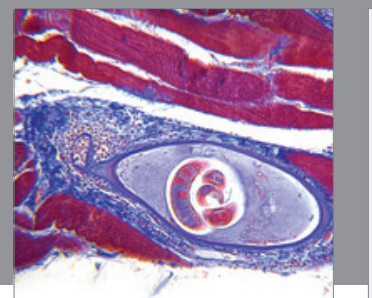

Gastroenterology

Research and Practice
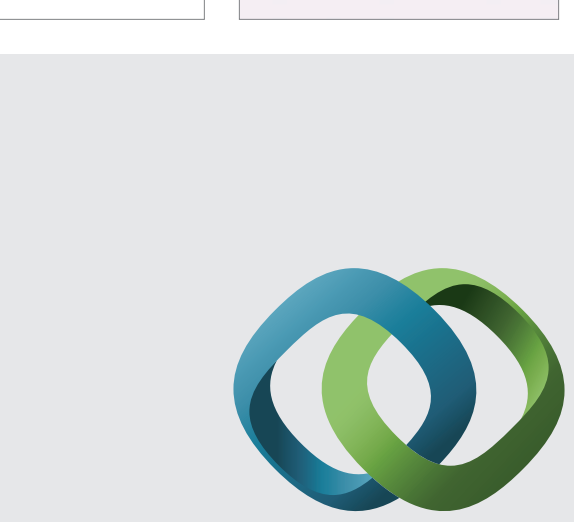

\section{Hindawi}

Submit your manuscripts at

http://www.hindawi.com
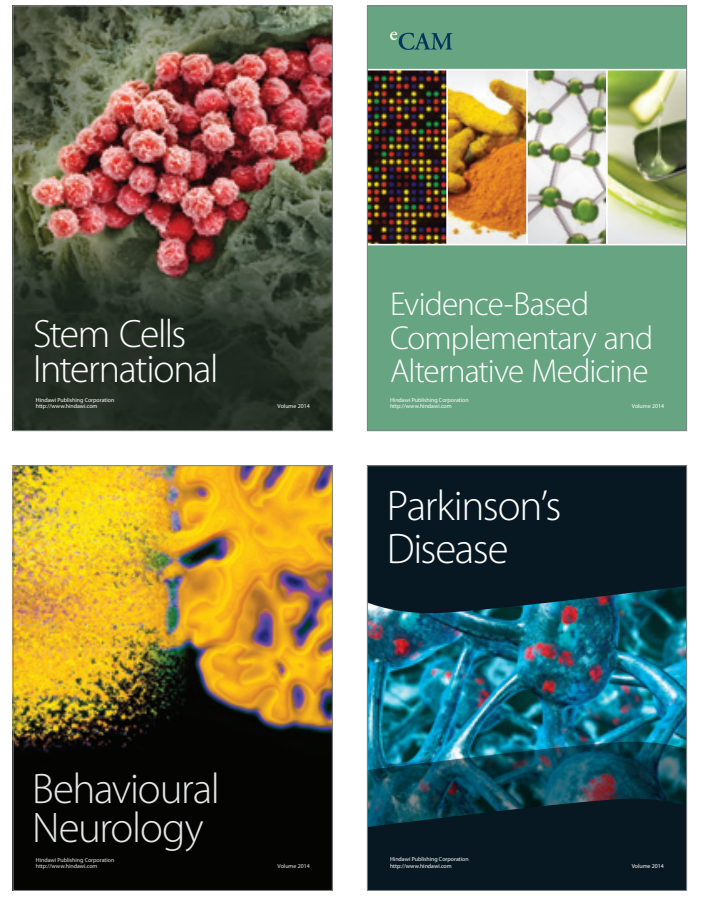
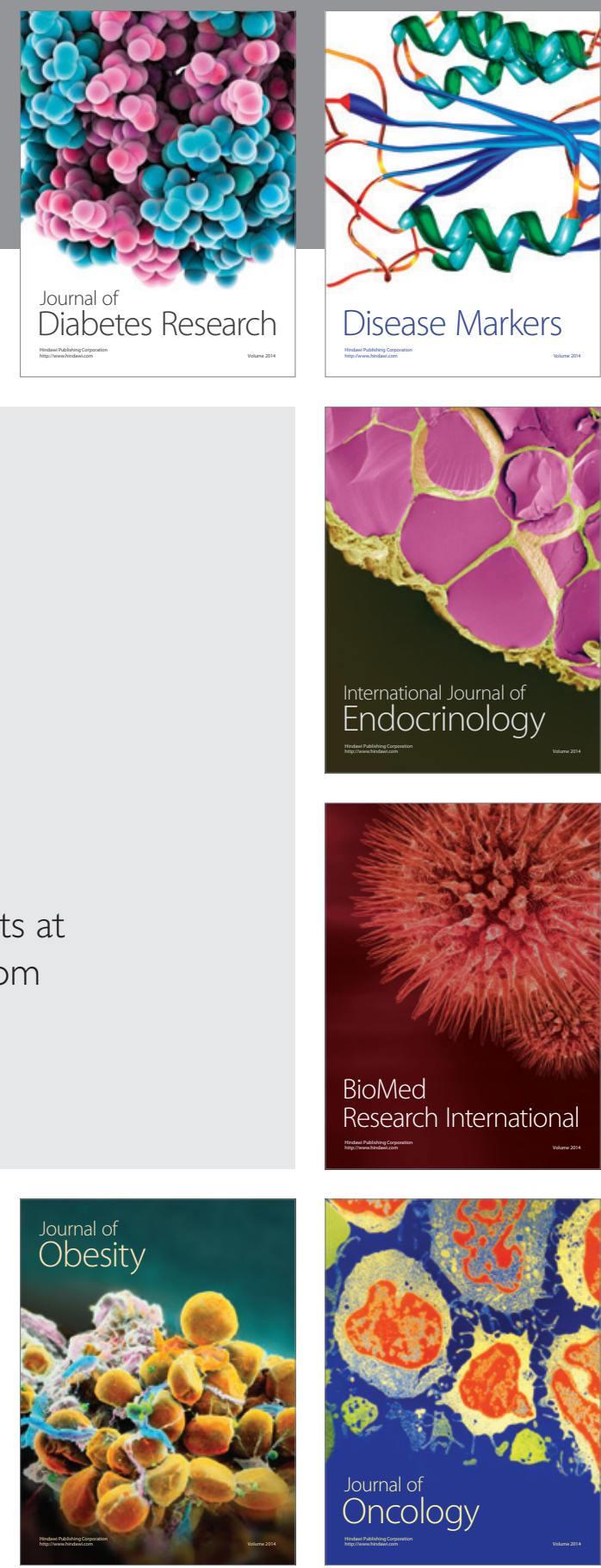

Disease Markers
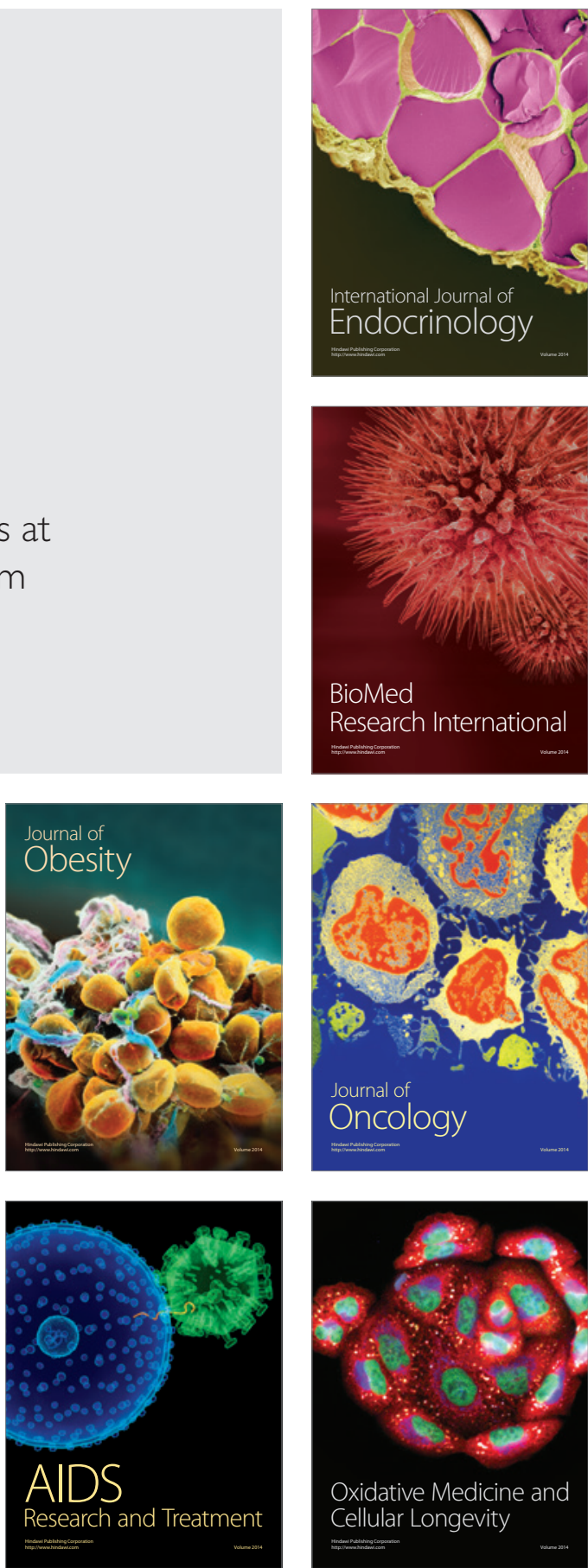